\title{
Research on artificial intelligence safety prediction and intervention model based on ship driving habits
}

\author{
Runnan Liu, Guangze Liu, Pengfei He, and Xingzhi Lin* \\ Computer and Information Engineering College, Guangxi Vocational Normal University, Nanning \\ 530007, China
}

\begin{abstract}
Based on the analysis of the causes of ship accidents, the development prospect and development direction of ship intelligent safe driving, the artificial intelligence safety prediction and intervention model is put forward. This model solves the problem of ship intelligent safety prediction by using intelligent analysis technology and network technology, and promotes the development of ship intelligence and ship safety navigation technology. Additionally, it expands the channels of obtaining information, connects the ship's mechanical and electrical equipment, collects, stores and analyzes the data reasonably, and constructs the intelligent analysis and processing platform of ship small-world data processing to implement intelligent intervention. What is impressive is that it makes ship navigation safer, more economical, more reasonable and optimized, and accelerates the development of ship artificial intelligence safe navigation.
\end{abstract}

Keywords: Driving habits, Safety pre-judgment, Intervention mode.

\section{Introduction}

The ship artificial intelligence safety prediction and intervention model, as a direction of the development of ship intelligence, completes the intelligent safety prediction and data collection of ships by recording the operation of ship drivers and the status of ship equipment for a long time, and combining artificial intelligence technology with network technology based on driving habits. By collecting the data of oncoming ship, climate information, and through artificial intelligence analysis, it provides a safer and economical route for the ship. In addition, it performs a long-term collection of driver operations, and makes intelligent intervention in advance before personnel operation to make the ship more intelligent. The intervention mode, that is, connecting the ship's mechanical and electrical equipment, so that the ship can not only obtain information, but also intelligently control its own mechanical and electrical equipment. As a result, when the ship is in danger, it ca $n$

\footnotetext{
* Corresponding author: $\underline{\text { lxz4562509@,qq.com }}$
} 
automatically control the ship through the ship intelligent intervention mode, such as automatic steering, automatic avoidance, emergency braking and so on, so as to reduce the economic losses and casualties caused by improper behavior.

\section{The overall framework of artificial intelligence security prediction and intervention}

Artificial intelligence safety prediction and intervention model, based on ship driving habits integrates many technologies, such as data analysis, automatic control and so on. The ship database is established to collect many kinds of information, such as crew driving habits, waterway information, etc. The information collected is passed through the intelligent analysis, and reasonable sailing advice are provided to the ship drivers to realize the ship safety prediction model. The integration of ship intelligent intervention module and automatic control technology can provide many functions for the ship, such as automatic collision avoidance, automatic control, emergency braking and so on. Through intelligent analyze data, directly control the internal mechanical and electrical equipment of the ship, realize the intelligent intervention model of the ship, and ensure the safety of the ship. The artificial intelligence safety prediction and intervention model consists of three modules: data collection, ship intelligent prediction module and ship intelligent intervention model. As shown in Figure 1.

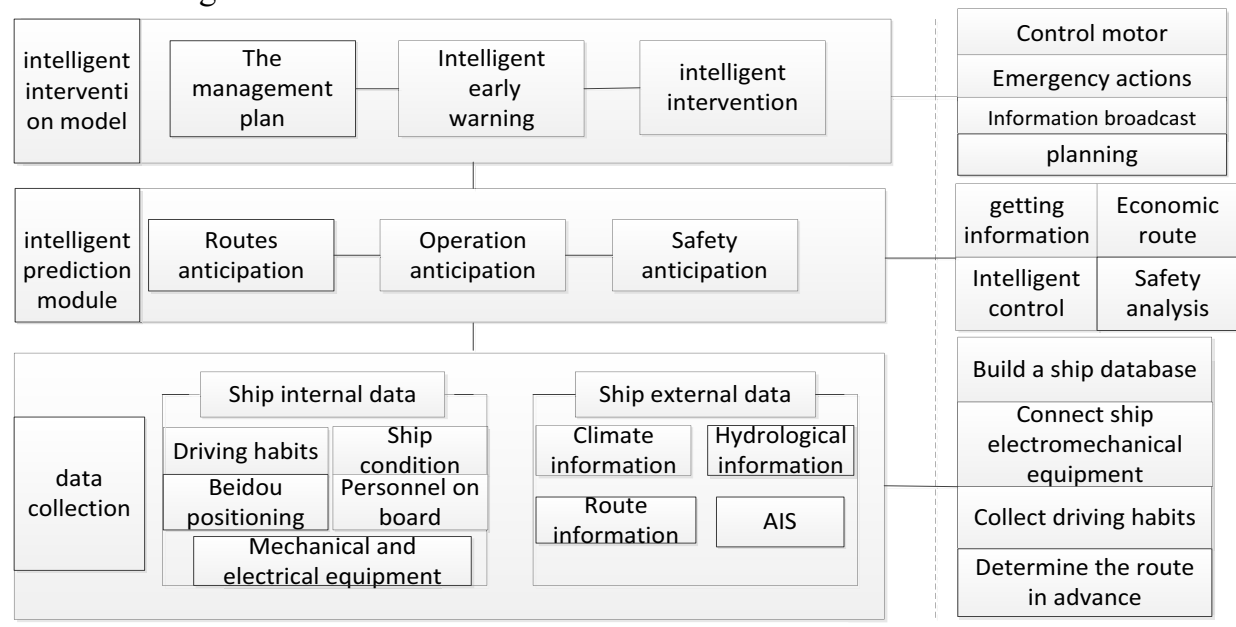

Fig. 1. Architecture diagram of security pre-judgment and intelligent intervention.

The first part is data collection module. It establishes the ship database, automatically obtains the navigation, and uses a variety of technologies to complete the information collection of the ship crew's driving habits and physical conditions. It connects the ship mechanical and electrical equipment, obtains the ship condition, ship mechanical and electrical equipment and other internal data, and collects a variety of external data such as climate information, water level information, route information and so on through a variety of information acquisition channels.

The second part deals with the ship intelligent prediction module. It uses the data of the data collection module, combined with safety model and collision avoidance rules for intelligent analysis, simulates navigation, calculates economic routes, ship navigation safety and other information, and uses information to provide data support for intelligent control.

The second part intelligent intervention module. It is responsible for making management plans, implementing the results of ship predictions, and realizing the functions 
of early warning and intervention. In addition, it establishes the information broadcast module, makes the information push more diverse, makes a plan to determine the applicable state of the ship's emergency risk aversion, and completes the intervention behavior by controlling the motor.

\section{Construction of ship's safe and intelligent navigation and safe driving system}

\subsection{Intelligent navigation prediction and intervention model based on driving habits}

Intelligent navigation prediction and intervention based on driving habits includes multi-mode data collection, intelligent learning, intelligent prediction of all kinds of situations and ship intelligent intervention control. The collection of multimode data can be divided into the collection of internal information of the ship and the collection of external information of the ship. In the interior of the ship, it is mainly necessary to collect the crew's driving habits and all aspects of the ship's mechanical and electrical equipment data. This requires the establishment of ship's SQL server for data partition, which can ensure operational efficiency; it is connected with the ship monitoring system and the ship's mechanical and electrical equipment to obtain crew operating habits and storage. For the exterior of the ship, many kinds of information such as the incoming ship, wind speed, climate and so on can be obtained intermittently through a variety of operations, such as network data, installation of sensors and so on. With regard to intelligent learning, genetic algorithm is an optimization algorithm that can be learned in the intelligent prediction of ships. It obtains the optimization and optimal solution through step-by-step screening and optimization, and determines the parameters such as initial population, fitness value and genetic operator, and the applicable value is the judgment standard that meets the requirements of iteration. Further, it achieves the optimal solution of ship operation prediction through continuous in-depth study. The prediction of the crew's operation intelligence not only needs to invoke the crew's operation habit, but also needs to compare the crew's driving habit through the intelligent learning analysis, after the multi-level repeated in-depth study, thus simplifying the ship's driving. As shown in Figure 2:

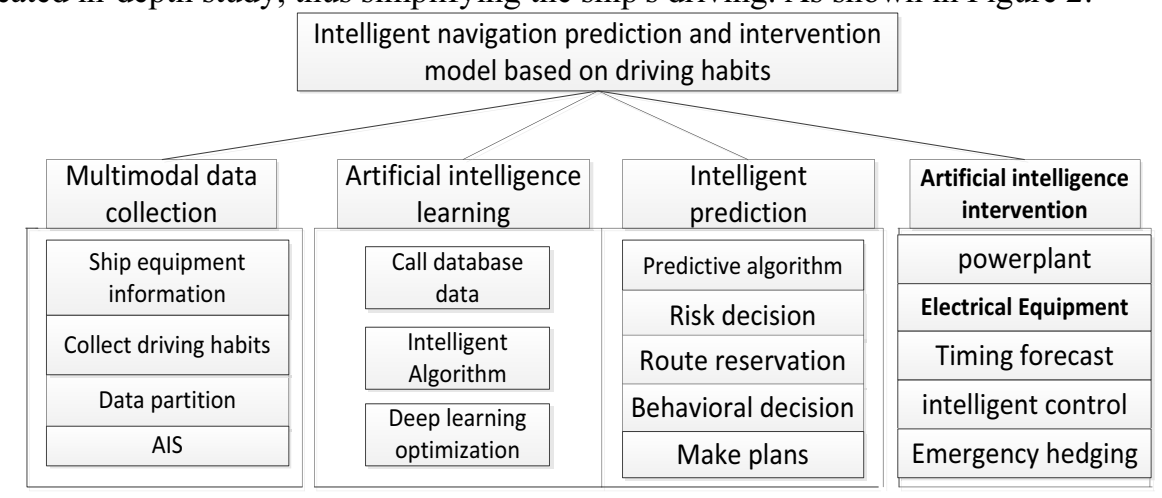

Fig. 2. Structure diagram of pre-judgment and intervention model.

The intelligent analysis relies on the study of ship artificial intelligence and the collection of ship data. By setting the threshold value through the external sensors and radars of the ship, the intelligent prediction of the ship sailing out of obstacles, danger and other conditions can be made, to decide the ship's operation decisions such as collision 
avoidance, braking, etc. The intelligent intervention control for ships can be divided into non-real-time intervention and intelligent intervention. Non-real-time intervention can be self-inspection through sensors and other equipment, to facilitate the maintenance of the ship crew. Intelligent intervention requires connecting the system to the ship's power plant and electrical equipment. After the failure of the early warning, the ship will operate in accordance with the pre-determined decision, until the ship is pre-determined to be safe.

Intelligent prediction and intervention depends on the collection of data and the continuous learning of ship intelligent system. Through continuous learning, a set of standards will be developed to compare the results of ship intelligent analysis standards, so as to obtain the level of environmental safety. You can also manually input the route, through the input of data, to avoid the ship off course. It provides more data and more economical and safe route information for ships through long-term collection and recording of route information. Ship intelligent intervention control requires the use of ship intelligent system and automation control technology, through the ship artificial intelligence intervention model and ship mechanical and electrical equipment connected. The intelligent early warning needs to make rules, judge the influencing factors, decide the grade by the size of the influencing factors, and decide the way and method of early warning according to the plan. The intelligent intervention is mainly to directly control the ship mechanical and electrical equipment. Rely on automatic control technology, the predicted results are sent to the ship's electromechanical equipment, which can to control the ship directly and complete the ship's avoidance, emergency braking and other control.

\subsection{Artificial intelligence safety prediction and intervention rules and operating procedures}

Artificial intelligence safety prediction and intervention depends on ship SQL sever, through long-term collection of crew driving habits and ship electromechanical data and other multi-mode data, connecting ship mechanical and electrical equipment, and constructing ship information collection system, so as to provide data support for prediction and intervention. For internal security, it mainly uses early warning mechanism to obtain unsafe information, and send it to the operator. For external security, after years of development, people have come to the conclusion that the two most important standards are the minimum security encounter distance (DCPA) and the minimum security encounter time (TCPA).

In the $\mathrm{XY}$ axis plane, let the geographical coordinates of the ship be $\left(\mathrm{X}_{0}, \mathrm{Y}_{0}\right)$, the speed $\mathrm{V} 0$, the geographical coordinates of the target ship $(\mathrm{T})\left(\mathrm{X}_{1}, \mathrm{Y}_{1}\right)$, the speed $\mathrm{V}_{1}$, and the

heading $\boldsymbol{\varphi}_{\mathbf{1}}$. The following formula is obtained from the geometric relation:

$$
\begin{array}{r}
\left\{\begin{array}{l}
V_{\mathrm{X} 0}=V_{0} \sin \varphi_{0} \\
V_{\mathrm{Y} 0}=V_{0} \cos \varphi_{0}
\end{array}\right. \\
\left\{\begin{array}{l}
\mathrm{V}_{\mathrm{X} 1}=\mathrm{V}_{1} \sin \varphi_{1} \\
\mathrm{~V}_{\mathrm{Y} 1}=\mathrm{V}_{1} \cos \varphi_{1}
\end{array}\right.
\end{array}
$$

From the geometric relationship, the relative motion velocities $\mathrm{V}_{\mathrm{Xr}}$ and $\mathrm{V}_{\mathrm{Yr}}$ of the target ship on the $\mathrm{X}$ axis and $\mathrm{Y}$ axis can be calculated. The formula of relative velocity (3) and the formula of relative distance between two ships (4)

$$
\begin{gathered}
\mathrm{v}_{\mathrm{r}}=\sqrt{\mathrm{v}_{\mathrm{xr}}^{2}-\mathrm{v}_{\mathrm{yr}}^{2}} \\
\mathrm{R}_{\mathrm{T}}=\sqrt{\left(\mathrm{x}_{\mathrm{t}}-\mathrm{x}_{0}\right)^{2}+\left(\mathrm{y}_{\mathrm{t}}-\mathrm{y}_{0}\right)^{2}}
\end{gathered}
$$


Minimum safety encounter distance and minimum safety encounter time. The minimum encounter distance between the target ship and the ship (DCPA) (5) and the minimum safe encounter time between the target and the ship (TCPA) (6)

$$
\begin{gathered}
=\text { DPCA }=\mathrm{R}_{\mathrm{T}} * \sin \left(\varphi_{1}-\varphi_{2}-\pi\right) \\
\mathrm{TCPA}=\mathrm{R}_{\mathrm{T}} * \cos \left(\varphi_{1}-\varphi_{0}-\pi\right) / \mathrm{V}_{\mathrm{r}}
\end{gathered}
$$

DCPA and TCPA are two important prediction standards in ship intelligent prediction. And then calculating the two prediction points of the ship itself through the data, according to the two key points and the navigation trajectory of the opposite ship, analyze the behavior, timing, amplitude and other information of collision avoidance, so as to achieve the purpose of reducing the occurrence of accidents. We can set a set of standards for ship intelligence, such as emergency measures should be taken when less than 2 nautical miles, emergency avoidance, siren warning, light warning and other measures can be used between 2 and 4 nautical miles. The operation rules of intelligent prediction and intervention of ships can be divided into pre-prediction and early warning and direct intervention. The focus of pre-prediction and early warning is the acquisition of information, through information to predict the danger degree of the event, and determine the intelligent judgment according to the danger degree. This requires setting the division of the risk level and the corresponding operation in advance. Direct intervention means that when the ship obtains the information of the opposite ship through AIS, the coordinate axis is established, and the collision risk degree, safe encounter time and other information of the ship are calculated with the geometric model, and then a mathematical model is established to simulate the encounter for prediction. The navigation state of the ship is changed through intelligent intervention. As shown in Figure 3:

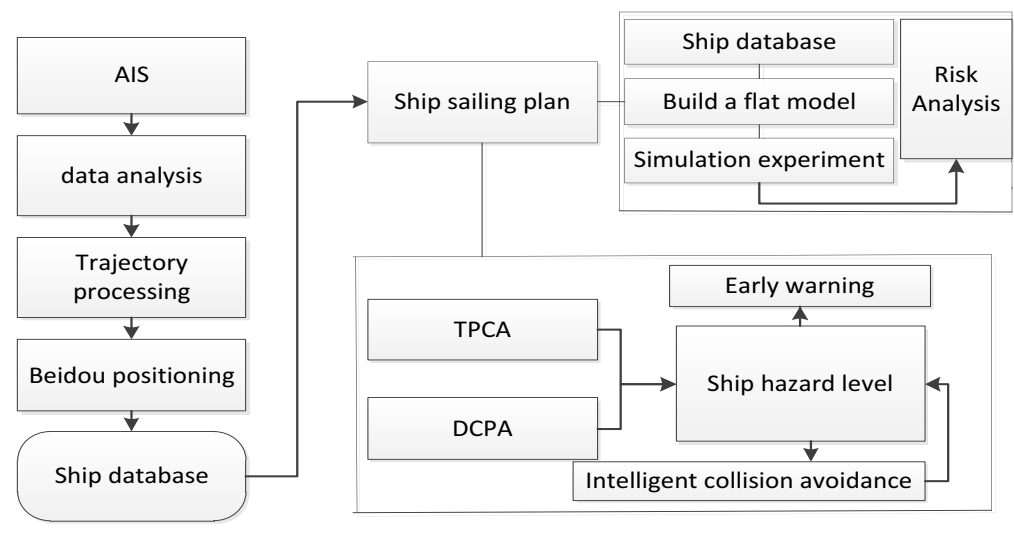

Fig. 3. Ship Intelligent Intervention Diagram.

\subsection{Data Integration and Automation system for ships safe driving}

Data integration is adopted in the design of intelligent navigation model based on ship safety. Data integration simplifies and simulates the operation of ship machinery and crew to form ship driving habits. In the process of ship running, the mechanical operation and human operation of the ship are the key factors that affect the safe navigation of the ship. Relevant research shows that $80 \%$ of the causes of navigation accidents are caused by human factors. Data integration stores a large amount of information about crew misoperation. Through the scientific analysis of the wrong operation information data, a 
new idea is provided for obtaining all kinds of crew driving habit information. The operation failure of ship machinery is not handled scientifically, which leads to navigation accident. The cause of the fault of marine mechanical equipment is not clear enough, the train of thought of troubleshooting is not clear enough, the problem is solved only from the point of view of experience, the equipment maintenance record is not fully mastered, which leads to the high-risk operation of marine machinery and equipment, which greatly increases the safety hidden danger of the ship. Through the analysis of the operation failure data of marine machinery and equipment, a scheme is provided for the formation of good habits in the operation of marine machinery and equipment. Data integration has the functions of spatial data management, assistant decision-making and visualization of operation habits, which makes it have a good advantage in the field of safe ship navigation. The use of data integration technology to establish a ship safety navigation system provides an intuitive visual form and decision support for ship safety navigation. The full use of data integration makes the ship accept more standardized inspection, improve the effective use of the ship, and improve the safety factor.

The core of ship automatic and safe navigation system is ship automation, navigation automation and avoidance automation. Ship sensor is the basis of ship automation, a set of advanced sensor applications, can quickly collect ship data and sense the ship environment, so that the equipment can operate efficiently. Ship automation needs the interchange of ship equipment, the access of the Internet of things and other technologies; navigation automation requires the comprehensive application of ship positioning, navigation and other technologies; collision avoidance automation requires a comprehensive analysis of heading, speed, distance, relative speed, danger degree and avoidance scheme. A large number of studies have shown that when there are problems in the ship avoidance system, the ship accident rate will increase greatly. Therefore, the automatic avoidance ability of the ship is very important. The application of ship AIS will make up for the lack of coverage of traditional radar, make collision avoidance more scientific, ensure the safety of ship navigation, and improve the level of navigation automation in an all-round way.

\section{Application and verification of artificial intelligence safety prediction and intervention model}

\subsection{Application of prediction and intervention model}

The ship intelligent prediction and intervention mode based on driving habits is based on SQL sever, computer artificial intelligence technology and automatic control technology to build a ship intelligence system and build a new small-world intelligent navigation mode. Intelligent prediction is mainly based on genetic algorithm and decision tree, and continuously analyzes and learns according to the crew's normal driving habits and all kinds of information conditions, so as to achieve the optimal solution of intelligent prediction. Emergency intervention depends on braking control technology and combines automation technology with intelligent technology to lay a physical foundation for ship emergency control. Specifically, the system first makes a decision, and then people decide the implementation of part of the decision, and finally the system realizes part of the decision, so as to achieve a new pattern of human-computer interactive control and partial control of the ship. In the ship intelligent prediction and intervention mode, the intelligent learning of the intelligent system runs through the whole model, and the intelligent learning is fully reflected in the structure, characteristics and subsequent development of the model, which makes the intelligence improve continuously. As a result, it can be used in more 
complex and extreme situations, and finally achieve a new situation of human-computer interaction and control.

\subsection{Prediction and intervention data verification}

Pass the data verification on the research of artificial intelligence safety prediction and intervention model based on ship driving habits. Through real-time monitoring of ship data, an intervention table for early warning of ship course deviation is obtained. Through multiple simulation experiments of two ships, a comparison chart of the ship safety intelligent control system is obtained.

Table 1. Artificial intelligence predictive intervention based on distance.

\begin{tabular}{|c|c|c|}
\hline Distance & Stage & Predictive intervention decision \\
\hline $\begin{array}{l}\text { 6-8 nautical } \\
\text { miles }\end{array}$ & $\begin{array}{l}\text { No collision hazard } \\
\text { phase }\end{array}$ & $\begin{array}{l}\text { Early warning and no measures are taken. Regular } \\
\text { lookout, free navigation }\end{array}$ \\
\hline $\begin{array}{l}\text { 4-6nautical } \\
\text { miles }\end{array}$ & $\begin{array}{l}\text { Gradual formation } \\
\text { of a collision hazard } \\
\text { stage }\end{array}$ & $\begin{array}{l}\text { Early warning should be taken, large-scale control } \\
\text { measures should be taken in advance, and large-scale } \\
\text { actions should be taken. }\end{array}$ \\
\hline $\begin{array}{l}\text { 2-4nautical } \\
\text { miles }\end{array}$ & $\begin{array}{l}\text { Forming an urgent } \\
\text { situation }\end{array}$ & $\begin{array}{l}\text { For the early warning of the horn of the incoming vessel, } \\
\text { a large-scale action shall be taken immediately. }\end{array}$ \\
\hline $\begin{array}{l}\text { 1-2nautical } \\
\text { miles }\end{array}$ & $\begin{array}{l}\text { Stage of imminent } \\
\text { danger }\end{array}$ & $\begin{array}{l}\text { For ships to avoid danger in an emergency, the } \\
\text { intelligence shall automatically take collision avoidance } \\
\text { measures, and the system shall carry out emergency } \\
\text { avoidance. }\end{array}$ \\
\hline $\begin{array}{l}\text { Within } \\
\text { 1nautical mile }\end{array}$ & Severe danger stage & $\begin{array}{l}\text { The ship's intelligent system quickly took over, the ship } \\
\text { issued an alarm, and immediately adopted a large-scale } \\
\text { risk avoidance control. }\end{array}$ \\
\hline
\end{tabular}

Table 2. Intervention table for early warning of ship course deviation.

\begin{tabular}{|c|c|c|c|}
\hline $\begin{array}{l}\text { Channel deviation } \\
\text { distance }\end{array}$ & $\begin{array}{l}\text { Channel deviation } \\
\text { angle }\end{array}$ & Whether to warn & Whether to intervene \\
\hline $2 \mathrm{~m}$ & $10^{\circ}$ & No warning & No intervene \\
\hline $5 \mathrm{~m}$ & $20^{\circ}$ & No warning & No intervene \\
\hline $8 \mathrm{~m}$ & $30^{\circ}$ & Safety warning & No intervene \\
\hline $10 \mathrm{~m}$ & $30^{\circ}$ & Safety warning & Smart intervention \\
\hline
\end{tabular}

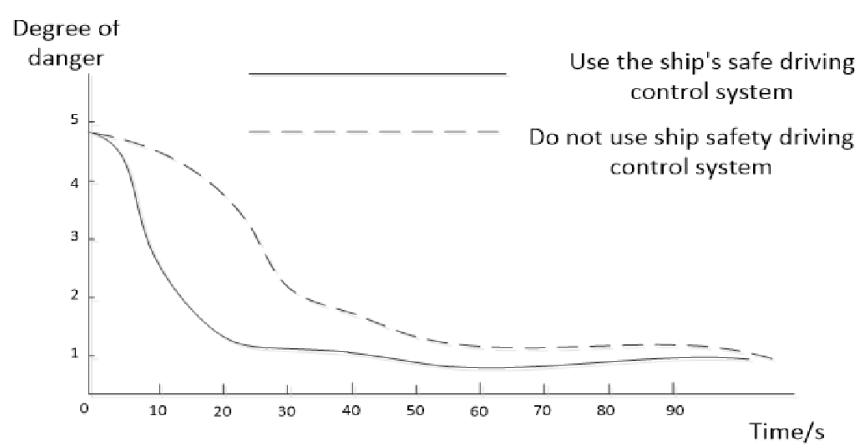

Fig. 4. Comparison diagram of ship safety intelligent control system. 
The feasibility of the research is verified by the comparative analysis of early warning analysis and simulated ship driving situation. The mode of ship intelligent prediction and intervention is based on the connection of ship mechanical and electrical equipment and the collection of ship data, and through the establishment of ship small world database. It uses decision tree and genetic algorithm to constantly analyze and learn the data, record every operation step and result of the crew, and constantly learn and modify until the optimal result is obtained.

\section{Conclusion}

The study of artificial intelligence safety prediction and intervention model based on driving habits is a research with social value and economic benefits, which plays a certain role in reducing the occurrence of ship safety accidents and ensuring the safe navigation of ships in our country. Through the long-term learning of artificial intelligence system, ships provide more optimized safety advice for crew members based on their driving habits. It uses network technology to obtain information to provide seafarers with a variety of functions, such as channel deviation early warning, hydroclimatic early warning and so on, and sets up a unified push mechanism to integrate the prediction of many kinds of information, make ship navigation more intelligent. Through long-term collection of multi-mode information and intelligent analysis, providing more data and information for ship driving makes ship driving simple and safe, which is an important direction of future development.

The work was supported by the project "Research on development and demonstration application of inland river green high-tech cargo ship" from Guangxi Innovation-driven Development Special Fund Project under Grant No. AA18118033, High Level Innovation Team and Outstanding Scholar Program of Guangxi Colleges and Universities under Grant (2019) No. 52-6 and the project "Research on ship's safe driving control system" from Guangxi Undergraduate Innovation and Entrepreneurship Training Program under Grant No.202014684001.

\section{References}

1. Wang Qun, Zhang Qingnian, YANG Jie, CONG Zhe, TU Min. Research on Navigation Behavior Decision Model of Unmanned Ship in Inland Waters [J]. Journal of Wuhan University of Technology,2021,45(01):44-48+53.

2. SHI Jianxiang, ZHANG Xiaoyan. The collision avoidance decision model of ship collision risk[J].Pearl River Water Transport, 2018 (18): 78-79.

3. DONG Di,LI Shiguo,CUI Tao,LIU Ying yan,NIE Tao. Analysis of ship navigation safety based on bridge resource management[J]. World shipping,2015,38(12):20-22.

4. Ning $\mathrm{Wu}$, Huang Haizun, Lin Xingzhi. Monitoring and Application Optimization of Power Consumption Situation of the Solar Photovoltaic System Inland Ship [J]. Marine Electric,2020,40(10):9-13.

5. ZHANG Jiguang, GAO Yang, TAO Zijian, CHEN Wang.Thinking on Innovation and Development of Smart Ship[J].Ship Design Newsletter,2019(02):8-10.

6. LEI Meilong,SHI Zhiguang,NI Xueyi. Narrow sense ship autopilot simulation system[J]. Journal of Shanghai Maritime University,1994(03):58-65. 